\title{
Correction: The anti-metastatic activity of collagenase- 2 in breast cancer cells is mediated by a signaling pathway involving decorin and miR-21
}

\author{
C Soria-Valles ${ }^{1} \cdot$ A Gutiérrez-Fernández ${ }^{1} \cdot \mathrm{M} \mathrm{Guiu}^{2} \cdot$ B Mari $^{3} \cdot$ A Fueyo $^{4} \cdot$ R R Gomis $^{2} \cdot$ C López-Otín $^{1}$
}

Published online: 3 May 2019

(c) Springer Nature Limited 2019

Correction to: Oncogene 33, 3054-3063 (05 June 2014) https://doi.org/10.1038/onc.2013.267, published online 15 July 2013
The original microRNA hybridization data for this article, which has been available for the scientific community upon request, has now been deposited in the GEO repository under accession number GSE124432.

2 Oncology Programme, Institute for Research in Biomedicine (IRB Barcelona), Barcelona, Spain

3 Centre National de la Recherche Scientifique and Université de Nice-Sophia-Antipolis, Institut de Pharmacologie Moléculaire et Cellulaire, Valbonne Sophia-Antipollis, France

4 193;rea de Fisiología, Departamento de Biología Funcional, Facultad de Medicina, Instituto Universitario de Oncología (IUOPA), Universidad de Oviedo, Oviedo, Spain 